\title{
Self-Consolidating Concrete Incorporating High Volume of Fly Ash, Slag, and Recycled Asphalt Pavement
}

\author{
Enad Mahmoud ${ }^{1), *}$, Ahmed Ibrahim ${ }^{2)}$, Hassan El-Chabib ${ }^{2)}$, and Varun Chowdary Patibandla ${ }^{2)}$
}

(Received October 12, 2012, Accepted April 13, 2013)

\begin{abstract}
The use of sustainable technologies such as supplementary cementitious materials (SCMs), and/or recycled materials is expected to positively affect the performance of concrete mixtures. However, it is imperative to qualify and implement such mixtures in practice, if the required specifications of their intended application are met. This paper presents the results of a laboratory investigation of self-consolidating concrete (SCC) containing sustainable technologies. Twelve mixes were prepared with different combinations of fly ash, slag, and recycled asphalt pavement (RAP). Fresh and hardened concrete properties were measured, as expected the inclusion of the sustainable technologies affected both fresh and hardened concrete properties. Analysis of the experimental data indicated that inclusion of RAP not only reduces the ultimate strength, but it also affected the compressive strength development rate. The addition of RAP to mixes showed a consistent effect, with a drop in strength after 3, 14, and 28 days as the RAP content increased from 0 to $50 \%$. However, most of the mixes satisfied SCC fresh properties requirements, including mixes with up to $50 \%$ RAP. Moreover, several mixes satisfied compressive strength requirement for pavements and bridges, those mixes included relatively high percentages of SCMs and RAP.
\end{abstract}

Keywords: recycled asphalt, self-consolidating concrete, fly ash and slag.

\section{Introduction}

Reinforced concrete (RC) structures constitute about $70 \%$ of today's infrastructures and for economical reasons structural engineers are under tremendous pressure to design smaller and shallower RC members. Such practice usually leads to heavily reinforced members especially in beamcolumn connections and in structures located in high seismic regions. Concrete in general consists of cement, water, and aggregates and if not designed and controlled properly, it can adversely affect the structural performance of RC structures due to its heterogeneous nature. One of the most important properties of concrete is its compressive strength. However, in some applications where members are heavily reinforced, concrete workability is as important. Thus, to alleviate any problems associated with concrete placement in narrow and congested $\mathrm{RC}$ members, concrete mixtures must be designed to be durable, workable, and achieve high compressive strength. In addition, global warming is a major problem for

\footnotetext{
${ }^{1)}$ Civil Engineering and Construction, Bradley

University, Peoria, IL 61625, USA.

*Corresponding Author; E-mail: emahmoud@bradley.edu

${ }^{2)}$ Civil Engineering and Construction, Bradley

University, Peoria, IL 61625, USA.

Copyright ( $\odot$ The Author(s) 2013. This article is published

with open access at Springerlink.com
}

todays and future development and most industries are shifting toward sustainable and green practices. Sustainable technologies such as supplementary cementitious materials (SCMs) and recycled materials are some of the attractive options to achieve green concrete.

One of the relatively new techniques to address concrete placement in congested RC members is using self-consolidating concrete (SCC). It is a highly workable concrete that can easily flow through heavily RC sections without the need for mechanical vibration. Its development represents one of the most significant recent advances in concrete technology (Khayat and Workability 1999; Zhu et al. 2001). Due to the high workability requirement, guidelines associated with the design of SCC recommended the use of chemical admixtures such as high-range water reducer (HRWR) and viscosity modifying admixtures (VMA) with minimum water content varying between 0.37 and 0.4 (EFNARC 2005). Limiting the $\mathrm{w} / \mathrm{c}$ to above 0.37 prevents the development of high compressive strength SCC mixtures, which is extremely needed for the design of narrow and heavily RC members. More importantly, using a w/c ratio higher than 0.37 in concrete mixtures might also affect the durability of such concrete.

Current guidelines ${ }^{1}$ (EFNARC 2005) also recommend the use of SCMs in SCC mixtures as partial replacement of Portland cement to enhance concrete workability and compressive strength. The concept of using high volume of

\footnotetext{
${ }^{1}$ Self-Consolidating Concrete, ACI Committee 237, ACI, Farmington Hills, MI.
} 
cementitious materials as partial cement replacement in SCC mixtures is not new and several researchers have incorporated up to $60 \%$ of fly ash in its design. Bouzoubaa and Lachemi (2001) investigated the compressive strength and fresh properties of SCC with up to $60 \%$ of cement replaced by class $\mathrm{F}$ fly ash. They concluded that class $\mathrm{F}$ fly ash slightly enhances concrete workability. However, the compressive strength of such concrete at early age was relatively low. Other researchers (Altoubat 2011; Papayianni and Anastasiou 2011; Yazici 2008; Amrutha et al. 2011) also investigated the feasibility of developing SCC with high volume of cement replaced by SCMs. However, they either limited their use to up to $60 \%$ in the case of fly ash, they did not use more than 2 types of cementitious materials, or they did not fully investigate the effect of such materials on all properties of SCC.

Gettu et al. (2004) investigated the development of fly ash based high-strength SCC. A 90-day compressive strength of about $100 \mathrm{MPa}$ has been obtained using the fly ash as a major constituent of concrete mixtures. Douglas et al. (Douglas et al. 2006) reported the possibility of developing SCC containing class F fly ash, which lead to reducing super-plasticizer (SP) dosage, increase workability, and increase overall chloride permeability resistance. The SCMs like silica fume and slag have a significant effect on the mechanical properties and durability of SCC (Lachemi et al. 2003). The study incorporated twenty-one concrete mixtures. Fly ash SCC mixtures had cement replacement of 40, 50 , and $60 \%$, while slag cement SCC mixtures had 50, 60, and $70 \%$ replacement, The w/c ranged from 0.35 to 0.45 and three different VMAs were included. The results showed that incorporating fly ash, slag cement, or VMA could successfully develop economical SCC with desired properties and three different economical mixtures were identified from fly ash, slag cement, and VMA-based SCC satisfying the targeted strength of $35 \mathrm{MPa}$.

Optimization and performance of air-entrained, SCC was reported by Khayat (2000). He indicated the possibility of proportioning air-entrained SCC of high stability and resistance to blockage. Optimized mixtures exhibited adequate engineering properties and durability. The Use of VMA's to enhance robustness of SCC was studied by Khayat (2012), focusing on the material characteristic of strength, which is defined as the insensitivity of SCC's fresh properties to material changes or batching errors during production. Hossain and Lachemi (2010) studied the fresh, mechanical, and durability characteristics of SCC with volcanic ash (VA). Twelve VA based concrete mixtures were developed by incorporating $0,20,30,40$, and $50 \%$ of VA as replacement of cement while keeping a constant total binder content of $400 \mathrm{~kg} / \mathrm{m}^{3}$. The water to binder ratio ranged from 0.35 to 0.45 . Fresh and hardened properties, as well as durability characteristics of the 12 mixtures demonstrate that VA can be used to develop SCC with acceptable properties and that it is possible to produce SCC by using 20-50\% VA as cement replacement. However, the authors indicated that replacement level of Portland cement by VA should be selected carefully in combination with water-to-binder ratio in order to achieve desired compressive strength, setting times, and durability.

Recycled asphalt pavement (RAP) use in construction of asphalt pavements is a common practice. Recent research studies examined the feasibility of incorporating RAP in Portland cement concrete (Huang et al. 2005, 2006). Two gradations of RAP (coarse and fine) materials were considered to replace the fresh aggregate from a control concrete mixture. The slump of concrete made with only coarse or fine RAP was lower than that of control concrete. While the slump of concrete made with both coarse and fine RAP was higher than that of control mix. The reason could be probably attributed to the asphalt coating around both coarse and fine RAP so that less water could be absorbed by the aggregates (Huang et al. 2005, 2006). The strength of concrete made with both coarse and fine RAP decreased the most among the RAP mixtures. The authors attributed the reduction in strength due to the fact that asphalt film around the aggregate particle was much softer than the concrete matrix and aggregate. Concrete made with only coarse RAP shows the least reduction in the strength of the RAP concretes and significant increase in toughness. Thus it might be more practical to incorporate a certain portion of coarse RAP to replace coarse aggregate (CA) (Huang et al. 2005, 2006).

Another research study (Kumar and Dhinakaran 2012) experimentally investigated concrete mixes containing recycled aggregate. The mechanical properties of recycled aggregate concrete (RAC) were compared with conventional concrete with SP, and found that the compressive strength of RAC was $\sim 90 \%$ that of conventional concrete. It was also found that usage of $<25 \%$ of recycled aggregate hardly affects the shear capacity of RC beams.

\section{Objectives and Tasks}

The objective of this study is to investigate the effect of sustainable technologies, fly ash, slag, and RAP, on fresh and hardened properties of SCC. To achieve this objective the following main tasks were performed:

(1) SCC mixes preparation: Table 1 summarizes the mix matrix used in this study. A total of 12 mixes were prepared, the mixes were selected such that a comparison of the effect of fly ash, slag, fly ash \& slag, and RAP on SCC mixes can be studied, in addition to the effect of RAP content on SCC, SCC-fly ash, SCC-slag, SCC-fly ash \& slag mixes. The ratios of the fly ash, slag, and RAP were selected based on the literature and the experience of the authors, to maximize the implementation of the waste-by-product materials in SCC.

(2) SCC laboratory testing: the experimental program in this study included:

(a) Fresh properties: slump flow-test. $\mathrm{T}_{50}, \mathrm{~J}$-Ring, and segregation.

(b) Hardened properties: compressive strength after 3,14 , and 28 days, and split tensile strength at 28 days. 
Table 1 SCC mix matrix.

\begin{tabular}{c|c|c|c}
\hline & $0 \%$ RAP & $25 \%$ RAP & M0\% RAP \\
\hline \hline $100 \%$ cement & Mix 1 & Mix 5 & Mix 10 \\
\hline $60 \%$ fly ash & Mix 2 & Mix 7 & Mix 11 \\
\hline $70 \%$ slag & Mix 3 & Mix 8 & Mix 12 \\
\hline
\end{tabular}

${ }^{a}$ RAP content indicates percent replacement of coarse aggregate with RAP.

(3) SCC mix strength requirement: the specifications of Illinois Department of Transportation (IDOT) were adopted to conduct this task. IDOT requires a minimum of $24 \mathrm{MPa} 14$ days compressive strength for concrete used in pavements, structures, \& massive structures, 22.1 MPa 14 days compressive strength for concrete used in pavement and bridge deck patching, and $27.5 \mathrm{MPa} 14$ days compressive strength for concrete in bridge superstructure.

\section{Experimental Study}

\subsection{Materials and Mixture Proportions}

Crushed limestone aggregate with nominal maximum aggregate size of $19 \mathrm{~mm}$ (3/4 in) and well-graded local sand were used as coarse and fine aggregates (FAs), respectively. The aggregate gradation is illustrated in Fig. 1. The relative specific gravity and absorption at saturated surface dry condition of CA were 2.68 and $1.2 \%$, respectively, whereas FA had a relative specific gravity of 2.67 , absorption at saturated surface dry condition of $2.50 \%$, and a fineness modulus of 3.07. Type I Portland cement having a specific gravity of 3.15 and conforming to ASTM requirements was used in the development of all concrete mixtures. Different binders incorporating ASTM type I cement and a combination of one or more SCMs including class $\mathrm{C}$ fly ash, and ground granulated blast furnace slag were also used in mixtures other than the controls. All SCMs, including fly ash and slag, conform to ASTM standards (ASTM C618-12 2012; ASTM C989/C989 M 2012) and have specific gravity values of 2.6, and 2.94, respectively. To achieve a flowable concrete made with a low w/c ratio, a highly efficient new

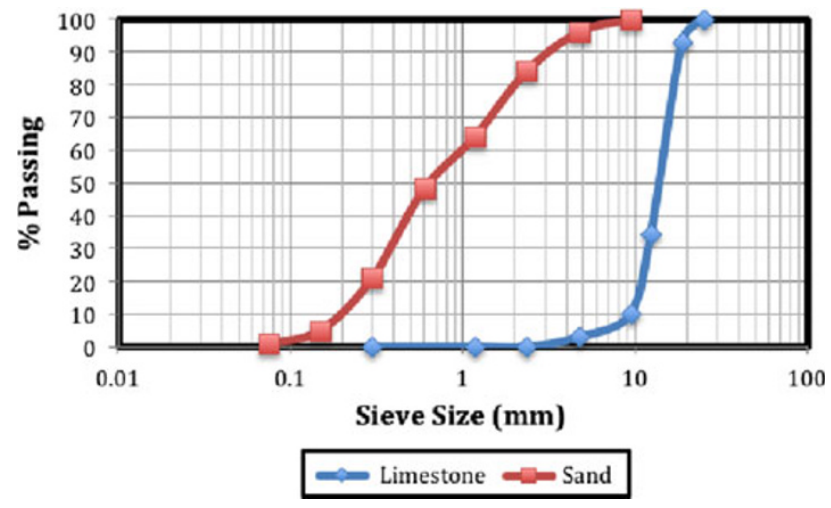

Fig. 1 Coarse and fine aggregate gradation. generation of polycarboxylic based HRWR agent (HRWRA) having a density of $1.1 \mathrm{~g} / \mathrm{cm}^{3}$ was employed. This type of HRWRA contains VMA that enhances concrete viscosity. Thus, no additional dosages of VMA were added to the mixtures. RAP materials were obtained from IDOT materials laboratory located in Peoria, Illinois. In order to keep gradation constant for all mixes regardless of RAP content, the RAP materials were sieved and separated into different sieve sizes. Different RAP sizes were then combined, with proportions selected such that the RAP gradation matches the gradation of the crushed limestone used in this study. The relative specific gravity of RAP was 2.44 (Table 2).

\subsection{Testing Procedure of SCC Mixtures}

The fresh properties of all concrete mixtures were measured to ensure that the concrete is flowable and stable. They were assessed using the slump flow and $T_{50}$ tests with and without the J-Ring and the segregation index (SI) test, respectively. The compressive strength at various ages (3, 14 , and 28 days), and split tensile strength were measured for hardened specimens. Preparation and curing of all test specimens was carried according to the ASTM standards (ASTM C618-12 2012).

\subsubsection{Slump-Flow and $T_{50}$}

Slump-flow and $T_{50}$ were used to measure the flowability and the rate of deformability of all mixes. The slump flow is based on the conventional slump test method and consists of using an inverted slump cone as per ASTM standards (ASTM C192-07 2007). The inverted cone was filled with SCC but no rodding or vibration was carried out. The cone was then lifted vertically and the spread of the concrete pie was measured. The average of two perpendicular diameters of the concrete spread after a full stop is considered as the slump flow value. On the other hand, the rate of concrete deformability was assessed using the $T_{50}$ test. This simple test consists of measuring the time needed for the SCC to reach a $50 \mathrm{~cm}$ spread during the slump flow test. In general, a slump flow value between 500 and $750 \mathrm{~mm}$ and a value of $T_{50}<7 \mathrm{~s}$ are considered acceptable for SCC design (EFNARC 2005).

\subsubsection{Segregation Index (SI)}

Due to the addition of SP to all mixes, mixes flowability was observed during the mixing process. The high flowability may lead to segregation, which is presented in a form of separation of large CA particles from the mortar matrix. Segregation is a major problem and should be avoided during the production of SCC to avoid any improper results. To overcome this problem, 
Table 2 Compositions and proportion of SCC mixtures.

\begin{tabular}{|c|c|c|c|c|c|c|c|c|c|}
\hline \multirow[t]{2}{*}{ Mix ID } & \multicolumn{5}{|c|}{ Cementitious materials $(\mathrm{kg})$} & \multirow{2}{*}{$\begin{array}{c}\text { Water }(\mathrm{kg}) \\
\mathrm{W}\end{array}$} & \multicolumn{3}{|c|}{ Aggregates $(\mathrm{kg})$} \\
\hline & $\mathrm{CM}$ & Cement & Fly ash & Slag & $\mathrm{W} / \mathrm{C}$ & & RAP & Coarse & Fine \\
\hline Mix 1 & 375 & 375 & 0 & 0 & 0.37 & 139 & 0 & 875 & 890 \\
\hline Mix 2 & 375 & 150 & 225 & 0 & 0.37 & 139 & 0 & 875 & 890 \\
\hline Mix 3 & 375 & 113 & 0 & 263 & 0.37 & 139 & 0 & 875 & 890 \\
\hline Mix 4 & 375 & 149 & 113 & 113 & 0.37 & 139 & 0 & 875 & 890 \\
\hline Mix 5 & 375 & 375 & 0 & 0 & 0.37 & 139 & 219 & 656 & 890 \\
\hline Mix 6 & 375 & 150 & 225 & 0 & 0.37 & 139 & 219 & 656 & 890 \\
\hline Mix 7 & 375 & 113 & 0 & 263 & 0.37 & 139 & 219 & 656 & 890 \\
\hline Mix 8 & 375 & 149 & 113 & 113 & 0.37 & 139 & 219 & 656 & 890 \\
\hline Mix 9 & 375 & 375 & 0 & 0 & 0.37 & 139 & 437.5 & 437.5 & 890 \\
\hline Mix 10 & 375 & 150 & 225 & 0 & 0.37 & 139 & 437.5 & 437.5 & 890 \\
\hline Mix 11 & 375 & 113 & 0 & 263 & 0.37 & 139 & 437.5 & 437.5 & 890 \\
\hline Mix 12 & 375 & 149 & 113 & 113 & 0.37 & 139 & 437.5 & 437.5 & 890 \\
\hline
\end{tabular}

all concrete samples were filled in a consistent technique with a strict quality control. In this study, a simple acceptable test, the SI test, is used to assess the ability of all SCC mixtures to resist segregation by visually inspecting the concrete pie after lifting the slump cone in the slump flow test, if there is no clear accumulation of CA particles/mortar at the center of the concrete pie and no free water flowing around its perimeter, the mixture is assigned a $\mathrm{SI}=0$ and it means that concrete can fully resist segregation. If the concrete mixture experienced an apparent accumulation of CA particles/mortar at the center of the concrete pie or a trace of free water flowing around its parameter, the concrete is assumed to have adequate resistance to segregation and $\mathrm{SI}=1$. In the case of obvious accumulation of CA particles/mortar or free water, the SI is set to 2 and the concrete is likely to segregate.

\subsubsection{J-Ring}

The J-Ring test is performed for all mixtures to measure the passing ability of the concrete through obstacles. The test is conducted in accordance with ASTM standards (ASTM 1611). The J-Ring test consists of measuring the average diameter of the spread concrete and the time needed to reach a circle of a $50 \mathrm{~cm}$ diameter after flowing through a ring attached to steel rods $10 \mathrm{~cm}$ apart as obstacles. The difference between the slump flow and J-Ring flow is an indication of the passing ability of the concrete. A difference $<100 \mathrm{~mm}$ is considered acceptable. The difference between the $T_{50}$ values measured using the J-Ring test and the slump flow test should not be more than 2-4 s. The orientation of the mold for the J-Ring test and for the slump flow test without the J-Ring shall be the same.

Table 3 Fresh properties of SCC mixtures.

\begin{tabular}{c|c|c|c|c}
\hline Mix ID & $T_{50}(\mathrm{~s})$ & $T_{50}$ with J-Ring $(\mathrm{s})$ & Segregation index $(\mathrm{SI})$ & $\mathrm{SP}\left(\mathrm{ml} / \mathrm{m}^{3}\right)$ \\
\hline \hline Mix 1 & 3 & 5 & $0-1$ & 1000 \\
\hline Mix 2 & 2 & 4 & $0-1$ & 1143 \\
\hline Mix 3 & 3 & 5 & 0 & 1000 \\
\hline Mix 4 & 1 & 10 & 0 & 714 \\
\hline Mix 5 & 9 & 1 & 0 & 1000 \\
\hline Mix 6 & 7.5 & 8 & 2 & 429 \\
\hline Mix 7 & 4 & 4 & 0 & 1143 \\
\hline Mix 8 & 3 & 7 & 0 & 714 \\
\hline Mix 9 & 3 & 15 & 0 & 857 \\
\hline Mix 10 & 4 & 4 & $0-1$ & 429 \\
\hline Mix 11 & 4 & 10 & 0 & 1429 \\
\hline Mix 12 & & 2 & & \\
\hline
\end{tabular}




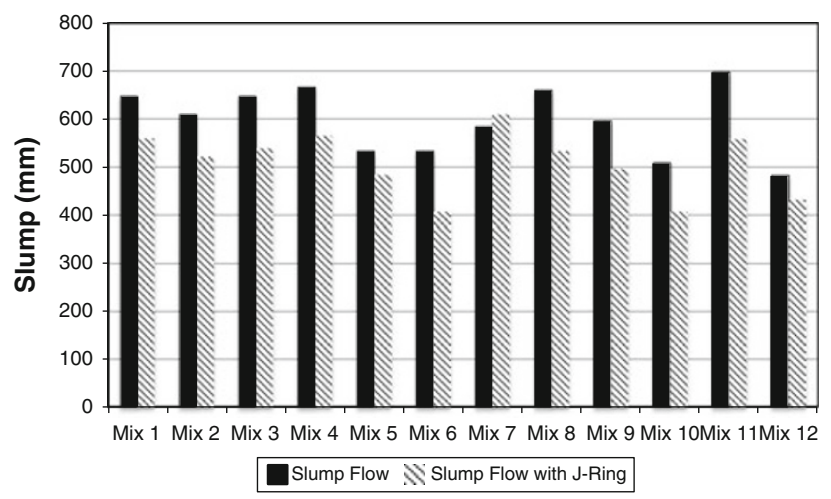

Fig. 2 Slump flow with and without J-Ring for all mixtures.

\subsubsection{Hardened Properties}

Compressive strength of the SCC mixes was determined in accordance with $\mathrm{ASTM}^{2}$ tests were conducted on $100 \times 200 \mathrm{~mm}$ cylindrical test specimens at the age of 3 , 14 , and 28 days for all the mixes. Splitting tensile strength was conducted on $150 \times 300 \mathrm{~mm}$ cylindrical test specimen to evaluate the tensile capacity provided by concrete according to ASTM standards (ASTM C 39/C39 M-10 2010; ASTM C 490/C 2009).

\section{Test Results and Discussion}

\subsection{Freshly Mixed SCC}

Published findings on the effect of a relatively low content of SCMs on the properties of fresh SCC indicated that fly ash and slag increase the workability of concrete (EFNARC 2005). Table 3 summarizes the fresh properties for all mixes. It is clear that Mix 2, Mix 8, and Mix 12 required the largest dosage of HRWRA to achieve the target slump flow. To achieve one mm of slump-flow, Mix 2, Mix 8, and Mix 12 require a dosage of HRWRA between 1875, 1730, $2960 \mathrm{ml} / \mathrm{m}^{3}$, respectively.

It is also important to note that the binary mixtures made with of $30 \%$ fly ash and $30 \%$ slag required $14 \%$ of HRWRA for mixes with $25 \%$ RAP replacement compared to the control mixture. The amount of HRWRA increased by $200 \%$ higher than that of the control mixture for mixes with $50 \%$ RAP replacement. On the other hand, mixtures incorporating fly ash required higher dosage of HRWRA than that of the control mixtures where the HRWRA in those mixtures were up to $30 \%$ higher than those of the control mixtures. The increase in flowability of concrete mixtures made with high content of slag and fly ash is attributed to the fact spherical shape of fly ash and slag particles, which enhance concrete flow. Table 3 also shows that although it was feasible to develop high flowable concrete with w/c of 0.37 , such concrete exhibits very low deformability as it is indicated by the high $T_{50}$ values of the mixtures. Most of the specimens were satisfied the target value of $T_{50}$. The low

\footnotetext{
${ }^{2}$ ASTM C 1621/C 1621 M-09b, Standard test method for passing ability of self-consolidating concrete by J-Ring. American Society for Testing and Materials, Pennsylvania, PA.
}

deformability is due to the fact that the HRWRA used in this study contains a viscosity-modifying agent in its production and using high dosages of such admixture to achieve a slump flow value higher than $500 \mathrm{~mm}$ enhances concrete viscosity as well, however the main reason for high viscosity of mixtures is the dense particle packing and low water content which lead to low deformability of concrete. This behavior was also observed visually while performing the slump-flow test in which, concrete took longer time to reach a full stop.

It is shown in Fig. 2, that the replacing the CA by 25 and $50 \%$ RAP reduced the slump flow values with J-Ring by 14 and $11 \%$ respectively for control mixtures (M1, M5, and M9). The effect of RAP also is extended to mixtures M6, and M10, which contain fly ash on the values of slump flow with J-Ring. The values are reduced by $22 \%$ compared to mixtures M2. Table 3 shows the SI for all mixtures. All
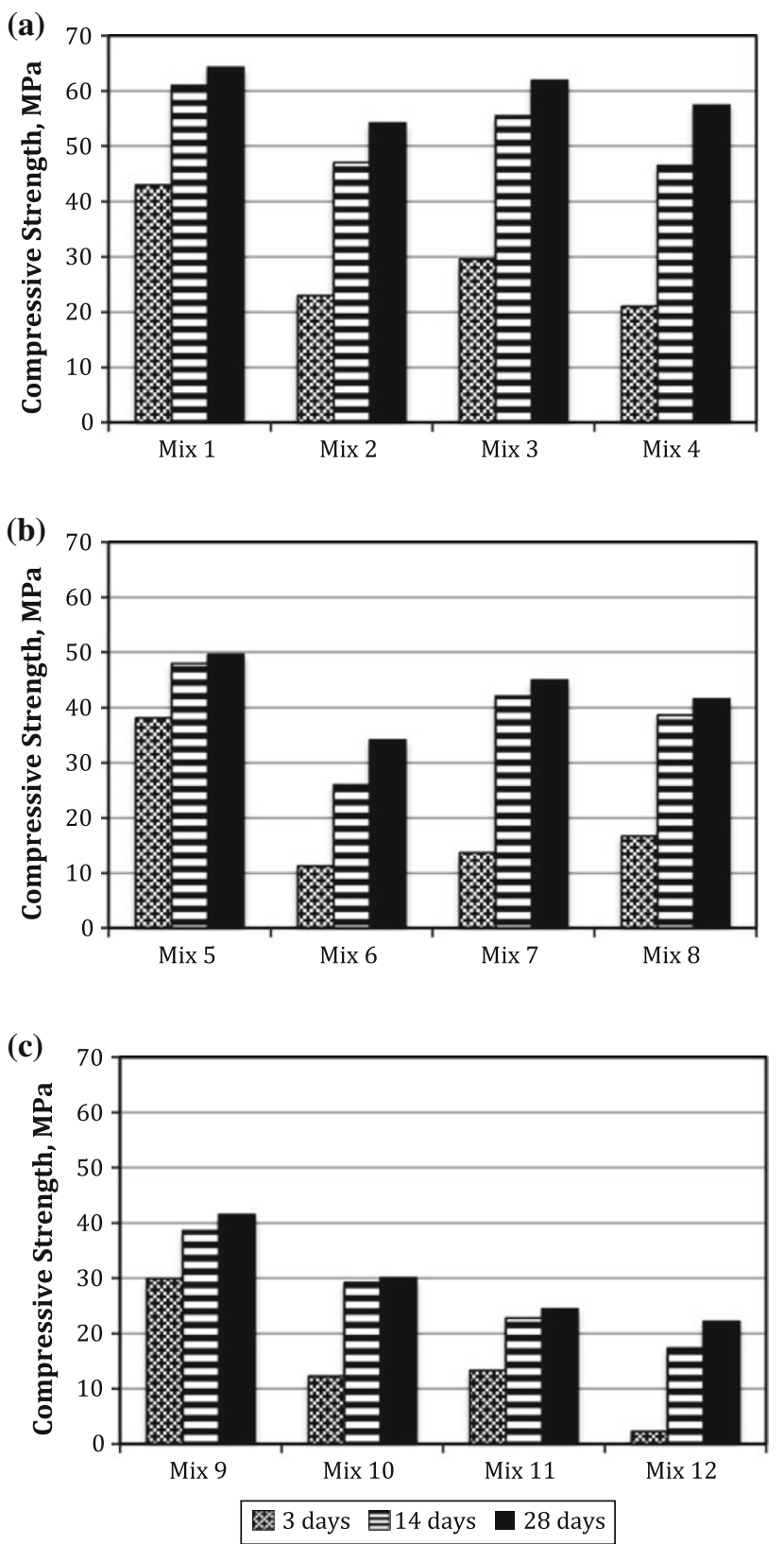

Fig. 3 SCC compressive strength: a $0 \%$ RAP content, b $25 \%$ RAP content, c $50 \%$ RAP content. 
(a)

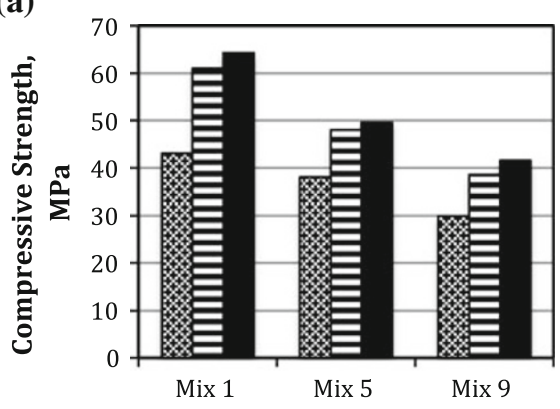

(c)

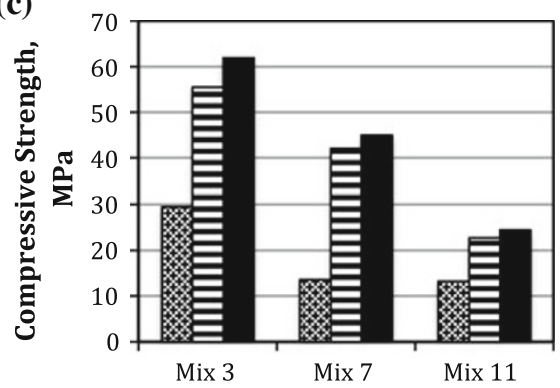

(b)

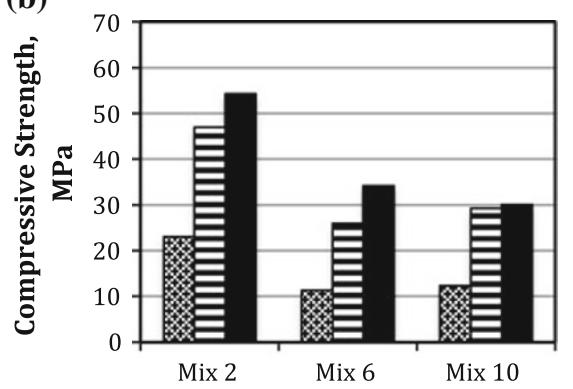

(d)

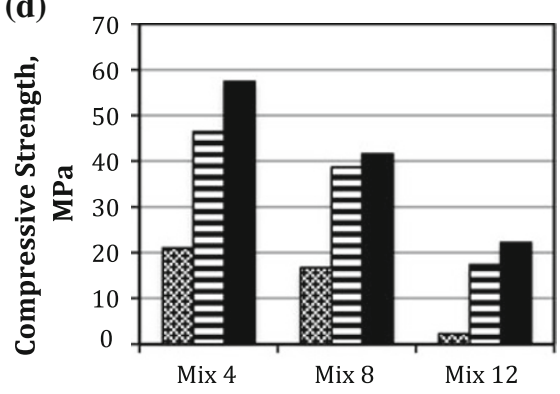

3 days $\equiv 14$ days $\mathbf{2 8}$ days

Fig. 4 SCC compressive strength: a SCC-control, b SCC-fly ash, c SCC-slag, d SCC-fly ash \& slag.

mixtures behaved well except mixtures M1, M3, and M12 showed some accumulation of the $\mathrm{CA}$ at the middle of the concrete pie. Figure 2 shows the values of slump flow with and without the J-Ring.

\subsection{Mechanical Properties of Hardened SCC}

Figure 3 summarizes the compressive strength of SCC mixes after 3, 14, and 28 days. Figure 3 a summarizes the effect of the inclusion of fly ash, slag and both fly ash \& slag in SCC mixes without RAP. The addition of slag to mixtures had minimum effect on the 14 and 28 days compressive strength as shown on Fig. 3c. The 14 days compressive strength was $91 \%$ of the control mixture strength, while the 28 days strength was $96 \%$ of the control mixture (M1) strength respectively, however, the 3-day compressive strength dropped significantly with the addition of slag by about $46.5 \%$. Mixes with fly ash exhibited the most reduction in strength; 46,23 , and $16 \%$ of the control mix after 3,14 , and 28 days respectively. SCC mixes with both fly ash and slag showed intermediate strength between fly ash only and slag only mixes after 14 and 28 days, but the 3 days strength was the lowest of all mixes. Figure $3 b$, c summarize the results for adding fly ash, slag, and fly ash \& slag to mixes with 25 and $50 \%$ RAP content respectively. The $25 \%$ RAP content mixes showed very similar trend in the rate of change in compressive strength compared to the $0 \%$ RAP mixes after 14 and 28 days. The trend was different for the $50 \%$ RAP mixes, the addition of fly ash resulted in the least drop in strength, while the addition of both fly ash and slag yielded the lowest strength.

In order to isolate the effect of RAP on SCC strength, the results shown in Fig. 2 were rearranged in Fig. 4; Fig. 4a shows the effect of adding RAP to control SCC mixes, Fig. $4 \mathrm{~b}$ shows the effect of adding RAP to SCC-fly ash mixes, Fig. 4c shows the effect of adding RAP to SCC-slag mixes, and Fig. 3d shows the effect of adding RAP to SCCfly ash and slag mixes. For all four cases the addition of RAP showed a consistent effect, with a drop in strength after 3, 14, and 28 days as the RAP content increased from 0 to $50 \%$.

Split tensile results are summarized in Fig. 5. The results are arranged to study the effect of adding RAP to SCCcontrol, SCC-fly ash, SCC-slag, and SCC-fly ash \& slag as shown in Fig. 5a-d respectively. The results clearly indicate that the split tensile strength dropped due to the addition of RAP. Two different trends were dictated in the split tensile strength reduction. In the case of SCC-control and SCC-fly ash (Figs. 5a and 5b) the $25 \%$ RAP content exhibited a larger reduction than the $50 \%$ RAP. The opposite was observed for the SCC-slag, and SCC-fly ash \& slag.

In addition to the importance of ultimate compressive strength of concrete, another important measure of concrete strength is the rate of compressive strength development. Figure 6 depict the compressive strength development of the 12 mixes in this study over the 28 days. The results are arranged to allow for studying the effect of adding RAP to a control SCC, SCC-fly ash, SCC-slag, and SCC-fly ash and slag. It's very important to mention that this analysis is based on the 28 days compressive strength of each mix. So, even though the compressive strength development rate is important, its only relevant if the mix satisfy target strength required by specifications, which will be studied in the next section. As shown in Fig. 6a the addition of RAP to control SCC mix increased the first 3 days strength development rate, while 3-14 days rate decreased, however, in all cases 
(a)

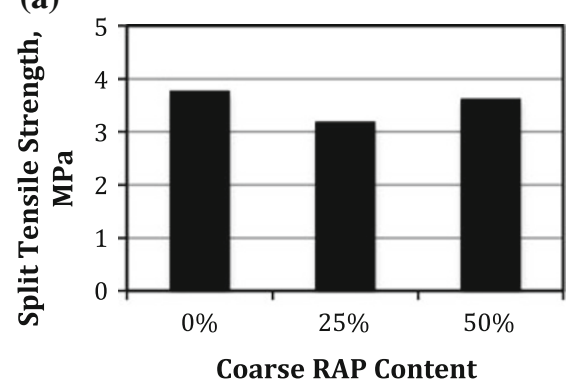

(c)

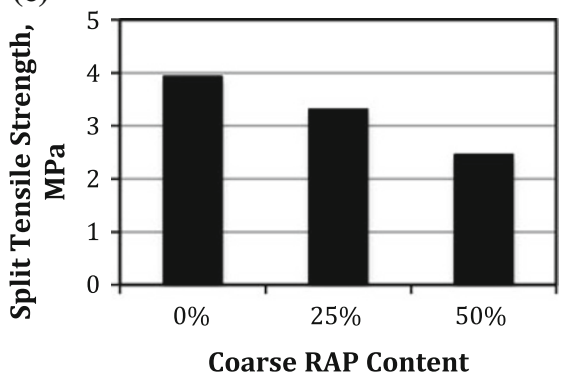

(b)

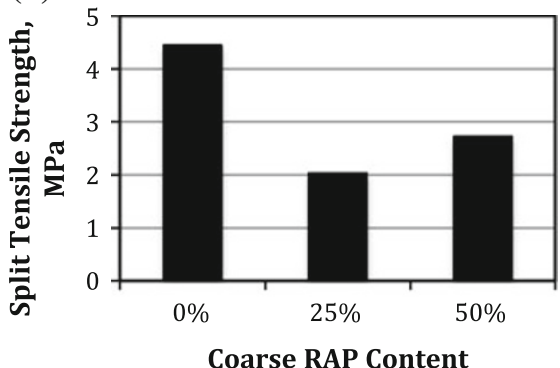

(d)

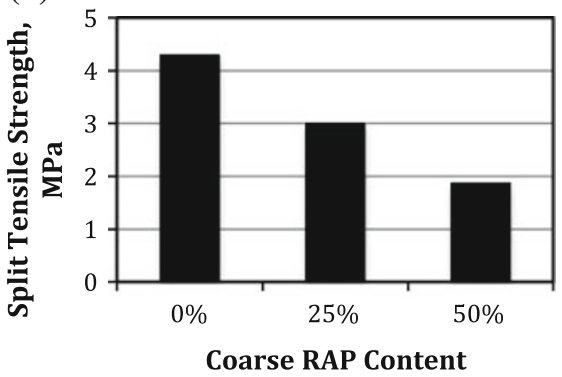

Fig. 5 SCC split tensile strength: a SCC-control, b SCC-fly ash, c SCC-slag, d SCC-fly ash \& slag.
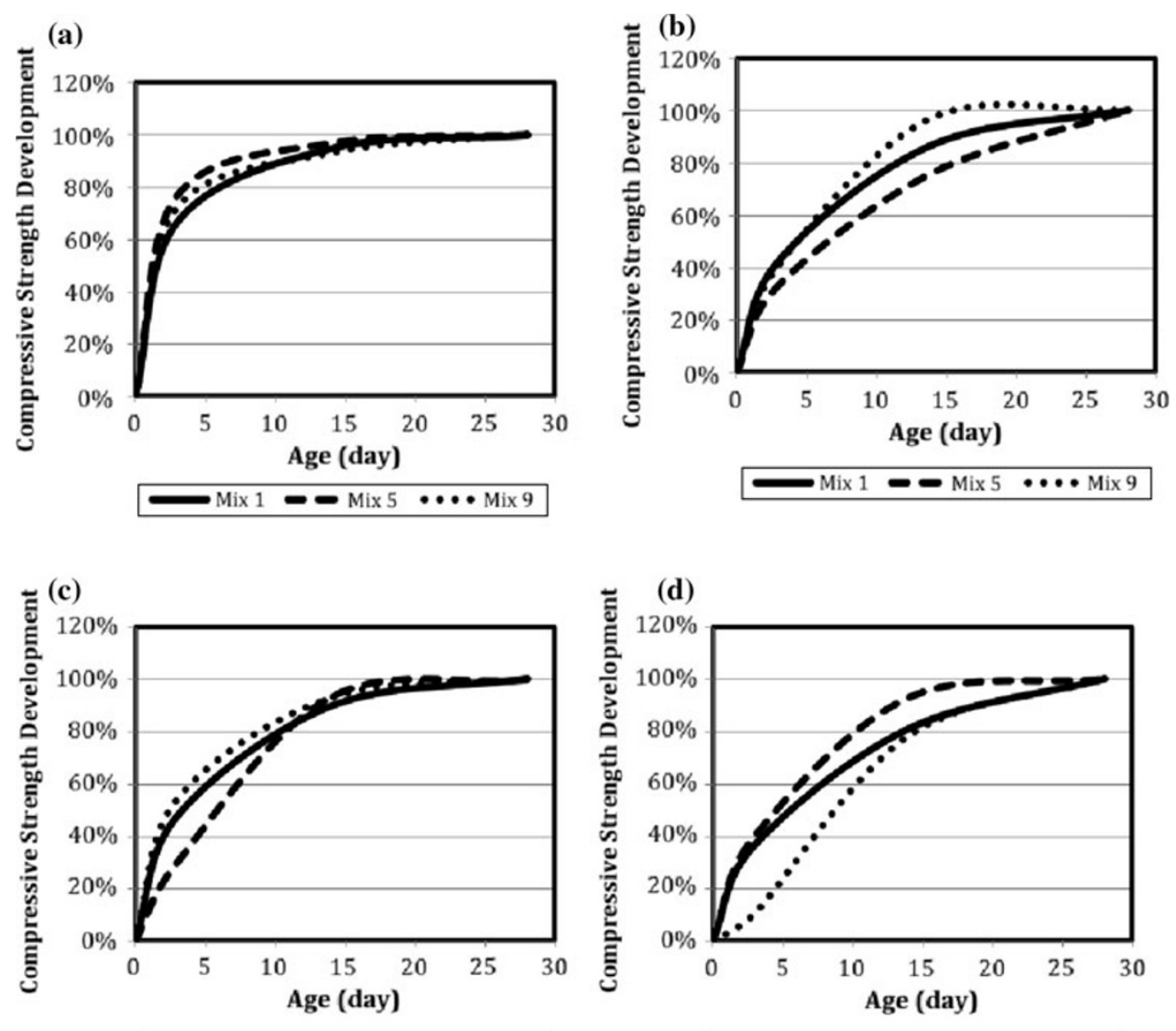

Mix $1-0 \operatorname{Mix} 5$ - 1 Mix 9

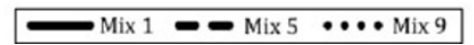

Fig. 6 SCC compressive strength development: a SCC-control, b SCC-fly ash, c SCC-slag, d SCC-fly ash \& slag.

more than $90 \%$ of the 28 days strength was developed within the first 14 days. The SCC-fly ash mix develop about $87 \%$ of its strength within 14 days, the addition of $25 \%$ RAP dropped that value to about $76 \%$, while more than $90 \%$ of the 28 days strength is developed within the first 14 days when $50 \%$ RAP content is used as shown in
Fig. 6b. As illustrated in Fig. 6c SCC-slag mixes develop around $90 \%$ of its full strength in the first 14 days, this percent improved to about $93 \%$ with the addition of RAP. Finally the SCC mixes with both slag and fly ash results showed a different trend, the main difference was the effect of RAP on the 3-days strength was around $10 \%$ for $50 \%$ 
Table 4 14-Days compressive strength IDOT criteria.

\begin{tabular}{c|c|c|c|c}
\hline Mix & $\begin{array}{c}\text { 14-Days compressive } \\
\text { strength }(\mathrm{MPa})\end{array}$ & $\begin{array}{c}\text { Application } \\
\text { patching }(>22.1 \mathrm{MPa})\end{array}$ & $\begin{array}{c}\text { Pavements \& structures } \\
(>24 \mathrm{MPa})\end{array}$ & $\begin{array}{c}\text { Bridge superstructure } \\
(>27.5 \mathrm{MPa})\end{array}$ \\
\hline \hline 1 & 61.0 & Satisfactory & Satisfactory & Satisfactory \\
\hline 2 & 47.0 & Satisfactory & Satisfactory & Satisfactory \\
\hline 3 & 55.5 & Satisfactory & Satisfactory & Satisfactory \\
\hline 4 & 46.5 & Satisfactory & Satisfactory & Satisfactory \\
\hline 5 & 48.0 & Satisfactory & Satisfactory & Satisfactory \\
\hline 6 & 26.0 & Satisfactory & Satisfactory & Not Satisfactory \\
\hline 7 & 42.1 & Satisfactory & Satisfactory & Satisfactory \\
\hline 8 & 38.6 & Satisfactory & Satisfactory & Satisfactory \\
\hline 10 & 38.6 & Satisfactory & Satisfactory & Satisfactory \\
\hline 11 & 29.2 & Satisfactory & Satisfactory & Satisfactory \\
\hline 12 & 22.8 & Satisfactory & Not Satisfactory & Not Satisfactory \\
\hline
\end{tabular}

RAP, however, the 14-days strength was around $80 \%$ or more for the three mixes.

The analysis in this section showed a general trend of reduction in SCC strength with the addition of RAP, fly ash, and slag in the different combinations described above, however, the important factor is the target strength and whether its achieved or not. The specifications of the IDOT were adopted to conduct this analysis. IDOT requires a minimum of $24 \mathrm{MPa}$ 14-days compressive strength for concrete used in pavements, structures, \& massive structures, 22.1 MPa 14-days compressive strength for concrete used in pavement and bridge deck patching, and 27.5 $\mathrm{MPa}$ 14 days compressive strength for concrete in bridge superstructure. Table 4 summarizes the results of checking the 14-days compressive strength of the 12 mixes in this study against IDOT criteria for each application type. The results indicate that $1 \mathrm{mix}$ failed the patching application requirement, 2 mixes failed the pavements and structures requirement and 3 mixes failed the bridge superstructures requirement. Several of the mixes that satisfied bridge superstructure requirements contained high levels of RAP and SCMs, such as Mix 7 (25\% RAP and $70 \%$ slag), and Mix 10 (50\% RAP and $60 \%$ fly ash).

\section{Summary and Concluding Remarks}

Twelve SCC mixes incorporating different proportions of RAP, fly ash and slag were prepared and tested in the lab, testing results indicated a general trend of drop in concrete strength with the increase of SCMs and RAP content. However, the reduction in strength was not sever in all cases, as many of the mixes based IDOT requirement for pavements and bridges. Based on the results obtained in this study and the analyses conducted the following observations were drawn:
- Using RAP with 25 and $50 \%$ produced SCC mixtures with an average slump flow and slump flow with J-ring of 597 and $509 \mathrm{~mm}$, respectively, however some mixtures showed values below the minimum.

- The inclusion of $70 \%$ slag to SCC mixes with up to $25 \%$ RAP had minimum effect on the 14 and 28 days compressive strength. However, the 3-days compressive strength dropped significantly by about $31 \%$.

- SCC mixes with both $30 \%$ fly ash and $30 \%$ slag showed intermediate strength between $60 \%$ fly ash only and $70 \%$ slag only mixes after 14 and 28 days.

- The addition of RAP to SCC, SCC-fly ash, SCC-slag, SCC-fly ash and slag showed a consistent effect, with a drop in strength after 3, 14, and 28 days as the RAP content increased from 0 to $50 \%$.

- Split tensile results clearly indicate that the split tensile strength reduced due to the addition of RAP.

- Inclusion of RAP in SCC, SCC-fly ash, SCC-slag, and SCC-fly ash and slag mixes not only reduce the ultimate strength, but it also affected the compressive strength development rate.

- SCC mixtures produced with combinations of $60 \%$ fly ash, $70 \%$ slag, $30 \%$ fly ash $+30 \%$ slag, and $25 \%$ RAP satisfied compressive strength requirement for IDOT pavements and bridges.

\section{Open Access}

This article is distributed under the terms of the Creative Commons Attribution License which permits any use, distribution, and reproduction in any medium, provided the original author(s) and the source are credited. 


\section{References}

Altoubat, S. (2011). Toward a sustainable SCC through the use of high volume fly ash and slag to reduce cement in SCC and the effect on its cracking potential. Middle East conference on sustainable building materials, University of Shargah, UAE.

Amrutha, N. G., Narasimhan, M. C., \& Rajeeva, S. V. (2011). Chloride-ion impermeability of self-compacting high volume of fly ash concrete mixes. International Journal of Civil \& Environmental Engineering IJCEE-IJENS V., 11(4), 29-35.

ASTM C 1611/C 1611 M-09b. (2009). Standard test method for slump flow of self-consolidating concrete. American Society for Testing and Materials, West Conshohocken, PA.

ASTM C618-12. (2012). Standard specification for coal fly ash and raw or calcined natural pozzolan for use in concrete. American Society for Testing and Materials, West Conshohocken, PA.

ASTM C 39/C39 M-10. (2010). Standard test method for compressive strength of cylindrical concrete specimens. American Society for Testing and Materials, West Conshohocken, PA.

ASTM C 490/C 490 M-09. (2009). Standard practice for use of apparatus for the determination of length change of hardened cement paste, mortar, and concrete. American Society for Testing and Materials, West Conshohocken, PA.

ASTM C192-07. (2007). Standard practice for making and curing concrete test specimens in the laboratory. American Society for Testing and Materials, 4(02), 117-123.

ASTM C989/C989 M. (2012). Standard specification for slag cement for use in concrete and mortars. American Society for Testing and Materials, West Conshohocken, PA.

Bouzoubaa, N., \& Lashemi, M. (2001). Self-compacting concrete incorporating high-volume of class f fly ash. Cement and Concrete Research, 31(3), 413-420.

Douglas, R. P., Bui, V. K., Akkaya, Y., \& Shah, S. P. (2006). Properties of Self-consolidating concrete containing class $f$ fly ash: With a Verification of the minimum paste volume method. ACI Materials Journal, 233, 45-64.

Gettu, R., Gomes, P. C. C., Agullo, L., \& Josa, A. (2004). Highstrength self-compacting concrete with fly ash: Development and utilization. ACI Materials Journal, 221, 507-522.
Hossain, K. M. A., \& Lachemi, M. (2010). Fresh, mechanical, and durability characteristics of self-consolidating concrete incorporating volcanic ash. Journal of Materials in Civil Engineering, 22(7), 651-657.

Huang, B., Shu, X., \& Burdette, E. G. (2006). Mechanical properties of concrete containing recycled asphalt pavements. Magazine of Concrete Research, 58(5), 313-320.

Huang, B., Shu, X., \& Li, G. (2005). Laboratory investigation of Portland cement concrete containing recycled asphalt pavements. Cement and Concrete Research, 35(10), 2008-2013.

Khayat, K. H. (2000). Optimization and performance of airentrained, self-consolidating concrete. ACI Materials Journal, 59(5), 526-535.

Khayat, K. H. (2012). Use of viscosity-modifying admixtures to enhance robustness of SCC. Dallas, TX: ACI Convention.

Khayat, K. H. (1999). Workability, Testing, and performance of self-consolidating concrete. ACI Materials Journal, 96(3), 346-354.

Kumar, P. S., \& Dhinakaran, G. (2012). Effect of admixed recycled aggregate concrete on properties of fresh and hardened concrete. Journal of Materials in Civil Engineering, 24(4), 494-498.

Lachemi, M., Hossain, K. M. A., Lambros, V., \& Bouzoubaa, N. (2003). Development of cost-effective self-consolidating concrete incorporating fly ash, slag cement, or viscositymodifying admixtures. ACI Materials Journal, 100(5), 419-425.

Papayianni, I., \& Anastasiou E. (2011). Development of selfcompacting concrete (SCC) by using high volume of calcareous fly ash. 2011 World of Coal Ash (WOCA) Conference, Denver, CO.

The European Federation of National Trade Associations, EFNARC. (2005). Specification and guidelines for self-compacting concrete, Association House, Farnham, U.K., 68.

Yazici, H. (2008). The effect of silica fume and high-volume class $\mathrm{C}$ fly ash on the mechanical properties, chloride penetration and freeze-thaw resistance of self-consolidating concrete. Journal of Construction and Building Materials, 22(4), 456-462.

Zhu, W., Gibbs, J. C., \& Bartos, P. J. M. (2001). Uniformity of in situ properties of self-compacting concrete in full-scale structural elements. Cement \& Concrete Composites, 23(1), 57-64. 